\title{
Association between metabolic syndrome and atherothrombotic stroke: a clinical study in tertiary care hospital, Minia, Egypt
}

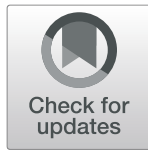

\author{
Amal T. Khafagy, Nermin A. Hamdy, Enas M. Hassan, Mohamed A. Yehia, Muhammad M. Ismail, \\ Mohamed M. Abdelkader and Nashwa M. Shawky *0
}

\begin{abstract}
Background: Stroke is the most common reason for disability and the third cause of mortality in the world per year. Metabolic syndrome (MetS) is known as an independent risk factor of coronary artery disease and stroke.

Aim of the work: To investigate the relationship between metabolic syndrome and risk of ischemic stroke, whether stroke patients with metabolic syndrome differ from other ischemic stroke patients in demographic variables, stroke presentation, stroke severity, neuroimaging, and prognosis.
\end{abstract}

Patients and methods: This is a hospital-based, prospective observational study. The study population constituted of patients with first-ever atherothrombotic ischemic stroke who were admitted to the neurology department within 6 months (between January $1^{\text {st }}, 2016$ and July $\left.1^{\text {st }}, 2016\right)$. Patients were subjected to full neurological examination, assessment of stroke severity using National Institute of Health Stroke Scale (NIHSS), screening for MetS components, brain imaging, transthoracic echocardiography, and carotid duplex.

Results: MetS was of higher frequency in atherothrombotic stroke patients compared to previous studies, more in females and older age. MetS with diabetes mellitus (DM) patients had the worst clinical presentation and the worst in-hospital outcome. High high-density lipoprotein cholesterol (HDL-C) was the predictor for worse clinical presentation.

Conclusion: The higher the number of MetS components, the higher the risk of ischemic stroke. High HDL-C was the predictor for worse clinical presentation. Thus, diagnosing and adequately managing MetS is an important step in preventing cerebrovascular disease.

Keywords: Atherothrombotic ischemic stroke, Metabolic syndrome, Risk factors

\section{Introduction}

Stroke is defined as an "acute neurologic dysfunction of vascular origin with symptoms and signs corresponding to the involvement of focal areas in the brain" [1]. Stroke is the most common reason of the disability that affects more than 700,000 individuals and the third cause of death in the world per year [2].

Ischemic stroke is the commonest type of stroke and constitutes $80 \%$ of all strokes. Approximately $45 \%$ of ischemic strokes are caused by small or large artery

\footnotetext{
* Correspondence: nooshamamdouh85@gmail.com

Department of Neurology, Minia University, Minia, Egypt
}

thrombus, $20 \%$ are embolic in origin, and others have an unknown cause [3].

Atherothromboticischemic stroke risk factors include arterial hypertension, DM, dyslipidemia, cigarette smoking, alcohol consumption, oldness, and male gender [4]. Patients with MetS are at two- to fourfold increased risk of stroke $[5,6]$.

According to the National Cholesterol Education Program Adult Treatment Panel III (NCEP ATP III) definition, MetS is present if three or more of the following five criteria are met: waist circumference (WC) > 40 inches (males) or 35 inches (females), BP $>130 / 85 \mathrm{mmHg}$, fasting triglyceride (TG) level > $150 \mathrm{mg} / \mathrm{dl}$, fasting HDL-C level $<40 \mathrm{mg} / \mathrm{dl}$ (males) 
or $50 \mathrm{mg} / \mathrm{dl}$ (females), and fasting blood sugar (FBS) $>100 \mathrm{mg} / \mathrm{dl}$ [7].

Each of the components of the MetS is associated with higher stroke risk to various degrees. This study was aimed to assess the relationship between MetS and risk of ischemic stroke, whether stroke patients with MetS differ from other ischemic stroke patients in demographic variables, stroke presentation, stroke severity, neuroimaging, and prognosis.

\section{Subjects and methods}

This is a hospital-based, prospective observational study, which was conducted in the Department of Neurology, Minia University Hospital. The study population constituted of patients with first-ever atherothrombotic ischemic stroke who were admitted to the neurology department within 6 months (between January $1^{\text {st }}, 2016$ and July $1^{\text {st }}$, 2016). Patients $\geq 40$ years old with a diagnosis of the first-ever symptomatic atherothrombotic ischemic stroke (according to the diagnostic criteria of Trial of Org 10172 in Acute Stroke treatment (TOAST) by neurological specialists) [8] were included. We excluded patients with a source of embolus (atrial fibrillation (AF), moderate to severe valvular heart disease, or intracarotid/ cardiac thrombus). We excluded also patients who presented with strokes with an undetermined etiology despite an extensive evaluation, history of previous stroke, and severe cardiorenal or nutritional disorder.

One hundred and thirteen patients were enrolled in this study. Patients were subjected to full neurological examination, assessment of conscious level using Glasgow Coma Scale (GCS), assessment of stroke severity using NIHSS at presentation and during their in-hospital stay, screening for MetS components, brain imaging using computed tomography (CT GE right speed, General Electric Healthcare, USA) and magnetic resonance imaging (Philips Achieva 1.5 tesla, USA), transthoracic echocardiography (Philips CX-50 Matrix, USA), and carotid duplex (Duplex Toshiba Xario 200).

Patients were classified into four groups: isolated MetS, MetS with DM, DM alone, and neither MetS nor diabetic. According to the 1999 World Health Organization (WHO) Consultation recommendations for the diagnosis of DM, patients with previously diagnosed or with FBS > $125 \mathrm{mg} / \mathrm{dl}$ were considered as having DM [9].

\section{Ethical consideration}

The study was approved by the Ethical Research Board of Minia School of Medicine, Egypt. Ethics approval date was November $24^{\text {th }}$, 2015. A written consent was taken from all the participants or their relatives after being informed about the objectives of the study, the examination, and the investigations. The confidentiality of their information was respected, and their right not to participate in the study was ensured.

\section{Statistical analysis}

Data analysis was done with Statistical Package for Social Sciences (released 2013, IBM SPSS Statistics for Windows, version 22.0; IBM Corp., Armonk, NY, USA). The differences between the groups were examined by an independent $t$ test, a one-way ANOVA test, and the chi-square test. Multiple linear logistic regression analysis was calculated for the outcome variable (having multiple brain ischemic lesions in brain imaging, GCS, and NIHSS) of the explanatory variables (MetS and its components).

\section{Results}

One hundred and thirteen patients diagnosed with firstever atherothrombotic ischemic stroke were included in this study: 60 males (53\%) and 53 females (47\%). Eightysix patients $(76 \%)$ had MetS criteria (including both isolated MetS and MetS with DM): 37 males (43\%) and 49 females (57\%) (Table 1).

Patients having MetS with DM were the oldest, while patients without MetS nor DM were the youngest group. The frequency of MetS with DM was significantly higher in female patients, while most of patients suffering from DM without MetS were males.

The frequency of HTN and central obesity was significantly higher in patients having MetS with DM, while low HDL-C frequency was significantly higher in isolated MetS patients (Table 1).

It was observed that patients having MetS with DM had the worst clinical presentation (the lowest GCS score and the highest NIHSS score) while patients without MetS nor DM had the best clinical presentation (the highest GCS score and the lowest NIHSS score); however, this difference did not reach the conventional level of statistical significance (Table 2).

Lesion multiplicity was considered by affecting more than one brain region. Table 3 shows that most of patients with isolated MetS and MetS with DM had single infarction in brain imaging.

Six patients (three had isolated MetS and three MetS with DM) were discharged upon their relatives' request against medical advice.

Patients were subjected to follow-up during their stay in the hospital (which is 7-10 days) using NIHSS and GCS. Improvement was considered by reduction of NIHSS with or without increase in GCS. Table 4 shows that patients having MetS with DM had significantly higher percentage of death than other groups, while higher percentage of improvement was in patients without MetS nor DM. 
Table 1 Sociodemographic, laboratory, and clinical characteristics of studied groups

\begin{tabular}{lllll}
\hline Variable & $\begin{array}{l}\text { Isolated MetS } \\
(n=36)\end{array}$ & $\begin{array}{l}\text { MetS } \\
\text { with DM } \\
(n=50)\end{array}$ & $\begin{array}{l}\text { DM without } \\
\text { MetS } \\
(n=10)\end{array}$ & $\begin{array}{l}\text { Neither } \\
\text { MetS nor } \\
\text { DM }(n=17)\end{array}$ \\
\hline $\begin{array}{l}\text { Age (mean, SD) } \\
\text { Sex (N, \%) }\end{array}$ & $62.14 \pm 11.28$ & $64.9 \pm 7.3$ & $59.29 \pm 9.67$ \\
$\quad$ Male & $18(50 \%)$ & $19(38 \%)$ & $8(80 \%)$ & $15(88 \%)$ \\
$\quad$ Female & $18(50 \%)$ & $31(62 \%)$ & $2(20 \%)$ & $2(12 \%)$ \\
SBP & $137.58 \pm 18.68$ & $136.34 \pm 20.43$ & $124.9 \pm 9.3$ & $125.53 \pm 15.1$ \\
DBP & $84.94 \pm 9$ & $82 \pm 12.65$ & $77.3 \pm 9.7$ & $82.24 \pm 8.1$ \\
FBS & $112.64 \pm 9$ & $204.96 \pm 88.56$ & $178.7 \pm 72$ & $107.1 \pm 10.58$ \\
WC & $98.5 \pm 12.4$ & $102.16 \pm 14.3$ & $79.1 \pm 9.93$ & $86.47 \pm 11.75$ \\
TGS & $113.97 \pm 53$ & $132.5 \pm 78.2$ & $99.3 \pm 26.56$ & $111.47 \pm 35.37$ \\
HDL-C & $32.89 \pm 10.97$ & $35.5 \pm 12.77$ & $41.5 \pm 14.1$ & $39.94 \pm 13.89$ \\
LDL-C & $125.7 \pm 39.3$ & $132.18 \pm 44.71$ & $133.8 \pm 36.37$ & $130.4 \pm 38.28$ \\
TC & $185.2 \pm 54.2$ & $200.34 \pm 62.9$ & $197.1 \pm 51.6$ & $0.048^{*}$ \\
\hline
\end{tabular}

Isolated MetS metabolic syndrome without diabetes mellitus, MetS with DM metabolic syndrome with diabetes mellitus, SBP systolic blood pressure, DBP diastolic blood pressure, FBS fasting blood sugar, WC waist circumference, TGS triglycerides, HDL-C high-density lipoprotein cholesterol, LDL-C low-density lipoprotein cholesterol, TC total cholesterol

*Significant result

In all studied patients, multiple linear regression analysis predicting GCS revealed that HDL-C level was the most significant predictor for GCS followed by TC and LDL-C (Table 5). In isolated MetS group, HDL-C level was the most significant predictor for GCS followed by WC but was statistically insignificant. In MetS with DM group, LDL-C level was the most significant predictor for GCS followed by TC and with tendency to significance HDL-C. In all studied patients, HDL-C level was significantly predicting NIHSS score at clinical presentation (Table 6). But in isolated MetS group, FBS level was the most predicting NIHSS score at clinical presentation but statistically insignificant. While in MetS with DM group, TC level was the most predicting NIHSS score at clinical presentation with tendency to significance followed by LDL-C.

\section{Discussion}

The frequency of MetS in this study (76\%) was higher than other previous studies [10-13]. Patients having MetS with DM were the oldest age $(67.64 \pm 11.34$ years old) $(P=0.023)$. This was consistent with Mathew, who found that prevalence of most individual factors of the

Table 2 Clinical assessment at presentation

\begin{tabular}{llllll}
\hline Variable & $\begin{array}{l}\text { Isolated } \\
\text { MetS } \\
(n=36)\end{array}$ & $\begin{array}{l}\text { MetS with } \\
\text { DM }(n=50)\end{array}$ & $\begin{array}{l}\text { DM without } \\
\text { MetS }(n=10)\end{array}$ & $\begin{array}{l}\text { Neither } \\
\text { MetS nor } \\
\text { DM }(n=17)\end{array}$ & $P$ \\
\hline GCS & $10.97 \pm 2.7$ & $10.38 \pm 3.4$ & $10.9 \pm 2.47$ & $11.35 \pm 2.87$ & 0.658 \\
NIHSS & $16.67 \pm 5.99$ & $17.9 \pm 5.5$ & $17.8 \pm .88$ & $15.76 \pm 5.57$ & 0.502 \\
\hline
\end{tabular}

GCS Glasgow Coma Scale Score, NIHSS National Institute of Health Stroke Scale Score, Isolated MetS metabolic syndrome without diabetes mellitus, MetS with $D M$ metabolic syndrome with diabetes mellitus
MetS increases with age [11]. Sixty-two percent of patients having MetS with DM were females. This is in agreement with Liu and colleagues, who showed that $70.3 \%$ of MetS patients with acute ischemic stroke were females [12]. Many studies showed that MetS increases the risk of ischemic stroke in females but not in males [14-16]. The higher frequency of MetS among ischemic stroke female patients in this study can be explained by the following: First, there is a true sex difference in prevalence which was approved by aforementioned studies. Second, perhaps the sex difference with respect to ischemic stroke and MetS resulted from sex differences in diagnostic criteria for MetS. We used waist circumference cutoff for male $\geq 94 \mathrm{~cm}$ and female $\geq 80 \mathrm{~cm}$. Third, TC levels in female patients with isolated MetS and MetS with DM were higher than in males of both corresponding groups. It is well known that lipid abnormalities are associated with atherosclerosis. MetS might encourage lipid abnormalities in females more than in males. Among the patients of MetS with DM group, $88 \%$ had central obesity, $82 \%$ had low HDL-C, and $74 \%$ were hypertensive. Similarly, Koren-Morag and

Table 3 Brain imaging in studied groups

\begin{tabular}{llllll}
\hline & $\begin{array}{l}\text { Isolated } \\
\text { MetS } \\
(n=36)\end{array}$ & DetS with $(n=50)$ & $\begin{array}{l}\text { DM without } \\
\text { MetS }(n=10)\end{array}$ & $\begin{array}{l}\text { Neither MetS } \\
\text { nor DM } \\
(n=17)\end{array}$ & $P$ \\
\hline $\begin{array}{l}\text { Single } \\
\text { lesion }\end{array}$ & $\begin{array}{l}26 \\
(72 \%)\end{array}$ & $38(76 \%)$ & $8(80 \%)$ & $11(65 \%)$ & 0.782 \\
$\begin{array}{l}\text { Multiple } \\
\text { lesions }\end{array}$ & $\begin{array}{l}10 \\
(28 \%)\end{array}$ & $12(24 \%)$ & $2(20 \%)$ & $6(35 \%)$ & \\
\hline
\end{tabular}

Isolated MetS metabolic syndrome without diabetes mellitus, MetS with DM metabolic syndrome with diabetes mellitus 
Table 4 Clinical outcome in studied groups

\begin{tabular}{llllll}
\hline & $\begin{array}{l}\text { Isolated } \\
\text { MetS } \\
(n=33)\end{array}$ & $\begin{array}{l}\text { MetS with } \\
\text { DM }(n=47)\end{array}$ & $\begin{array}{l}\text { DM without } \\
\text { MetS }(n=10)\end{array}$ & $\begin{array}{l}\text { Neither MetS } \\
\text { nor DM } \\
(n=17)\end{array}$ & $P$ \\
\hline Died & $\begin{array}{l}10 \\
(27.8 \%)\end{array}$ & $24(48 \%)$ & $3(30 \%)$ & $4(23.5 \%)$ & $0.029^{*}$ \\
Stable & $\begin{array}{l}11 \\
(30.5 \%)\end{array}$ & $11(22 \%)$ & $1(10 \%)$ & $1(5.9 \%)$ & \\
Improved & $\begin{array}{l}12 \\
(33.3 \%)\end{array}$ & $12(24 \%)$ & $6(60 \%)$ & $12(70.6 \%)$ & \\
& & & & \\
\hline
\end{tabular}

Isolated MetS metabolic syndrome without diabetes mellitus, MetS with DM metabolic syndrome with diabetes mellitus

*Significant result

colleagues found that the higher the number of MetS components, the higher the risk of ischemic stroke [15]. Seventy-six percent of MetS with DM patients and $72 \%$ of patients with isolated MetS had a single brain lesion. This is against Kotani and colleagues, who found that MetS had a significant positive association with multiple lesions of intracranial atherothrombotic stroke in females, but not males [17]. This could be attributed to that $69 \%$ of the studied patients had infarction affecting more than one lobe (large single infarction). It was found that high HDL$\mathrm{C}$ was the predictor for worse clinical presentation (lower GCS and higher NIHSS). This can be attributed to that HDL-C levels may not expect functionality and anti-inflammatory properties of HDL-C [18]. HDL undergoes prominent structural and functional modifications in the acute phase and inflammation restricting the anti-inflammatory role of HDL-C but also with the conception of proinflammatory HDL-C $[19,20]$. This is supported by Zeljkovic and colleagues, who reported that acute ischemic stroke patients had increased amount of small-sized HDL-C particles [21].

Table 5 Multiple linear regression analysis predicting GCS in all studied patients

\begin{tabular}{lllll}
\hline Variable & $\begin{array}{l}\text { Standardized } \\
\text { coefficient }\end{array}$ & $\begin{array}{l}\text { Part } \\
\text { correlation }\end{array}$ & $\begin{array}{l}\text { Partial } \\
\text { correlation }\end{array}$ & Sig \\
\hline HDL-C & -0.487 & -0.277 & -0.282 & $0.004^{*}$ \\
TC & 1.059 & 0.232 & 0.239 & $0.014^{*}$ \\
LDL-C & -0.722 & -0.203 & -0.211 & $0.031^{*}$ \\
WC & -0.184 & -0.172 & -0.180 & 0.067 \\
TGS & -0.227 & -0.159 & -0.167 & 0.089 \\
SBP & -0.136 & -0.092 & -0.097 & 0.323 \\
DBP & 0.133 & 0.087 & 0.092 & 0.351 \\
Age & -0.080 & -0.076 & -0.080 & 0.417 \\
FBS & 0.027 & 0.024 & 0.026 & 0.796
\end{tabular}

GCS Glasgow Coma Scale Score, SBP systolic blood pressure, DBP diastolic blood pressure, FBS fasting blood sugar, WC waist circumference, TGS triglycerides, $H D L-C$ high-density lipoprotein cholesterol, LDL-C low-density lipoprotein cholesterol, TC total cholesterol

*Significant result
Table 6 Multiple linear regression analysis predicting NIHSS in all studied patients

\begin{tabular}{lllll}
\hline Variable & $\begin{array}{l}\text { Standardized } \\
\text { coefficient }\end{array}$ & $\begin{array}{l}\text { Part } \\
\text { correlation }\end{array}$ & $\begin{array}{l}\text { Partial } \\
\text { correlation }\end{array}$ & Sig \\
\hline HDL-C & 0.374 & 0.212 & 0.217 & $0.026^{*}$ \\
SBP & 0.191 & 0.129 & 0.134 & 0.173 \\
TC & -0.572 & -0.125 & -0.130 & 0.185 \\
LDL-C & 0.399 & 0.112 & 0.117 & 0.236 \\
Age & 0.103 & 0.098 & 0.102 & 0.301 \\
TGS & 0.104 & 0.073 & 0.077 & 0.438 \\
WC & 0.064 & 0.060 & 0.063 & 0.524 \\
DBP & -0.070 & -0.046 & -0.048 & 0.628 \\
FBS & 0.016 & 0.014 & 0.015 & 0.880 \\
\hline
\end{tabular}

NIHSS National Institute of Health Stroke Scale Score, SBP systolic blood pressure, DBP diastolic blood pressure, FBS fasting blood Sugar, WC waist circumference, TGS triglycerides, HDL-C high-density lipoprotein cholesterol, LDL-C low-density lipoprotein cholesterol, TC total cholesterol

*Significant result

\section{Conclusions and recommendations}

In this study, MetS was of higher frequency in ischemic stroke patients compared to other previous studies, more in females and older age. The higher the number of MetS components, the higher the risk of ischemic stroke. High HDL-C was the predictor for worse clinical presentation. TC and LDL-C were also involved as main predictors for clinical presentation in MetS with DM group. Thus, diagnosing and adequately managing MetS is an important step in preventing cerebrovascular disease. So, there is a need to target the population with one or more components of MetS as they are at high risk of developing stroke in the future. More intensive lifestyle changes and management protocols (pharmacological treatment directed at decreasing insulin resistance, HTN, weight gain, and dyslipidemia) may be required in these patients for controlling the components of the syndrome. Further multicenter prospective cohort study with large sample size is needed to further investigate the relationship between MetS and ischemic stroke for its primary and secondary prevention. Further studies are needed for long-term follow-up in order to assess the long-term prognostic significance of MetS. More research is needed to clarify the role of HDL-C in stroke.

\section{Abbreviations}

AF: Atrial fibrillation; BP: Blood pressure; DBP: Diastolic blood pressure; DM: Diabetes mellitus; FBS: Fasting blood sugar; GCS: Glasgow Coma Scale; HDL-C: High-density lipoprotein cholesterol; HTN: Hypertension; LDL-C: Lowdensity lipoprotein cholesterol; MetS: Metabolic syndrome; NCEP ATP III: National Cholesterol Education Program Adult Treatment Panel III; NIHSS: National Institute of Health Stroke Scale; SBP: Systolic blood pressure; SD: Standard deviation; TC: Total cholesterol; TG: Triglycerides; TOAST: Trial of Org 10172 in Acute Stroke Treatment; WC: Waist circumference; WHO: World Health Organization 


\section{Acknowledgements}

Not applicable.

\section{Author's contributions}

NA recruited the cases and collected all the needed data. AK, NH, EH, MY, $\mathrm{MI}$, and MA revised the clinical data obtained and the results. Finally, NA wrote the manuscript which was revised by the other authors to be ready for publication. NA is the corresponding author who is responsible for the publication. All authors read and approved the final manuscript.

\section{Funding}

No funding was obtained from any institution for our study.

\section{Availability of data and materials}

Data can be available for publication only by special approval from the Minia University.

\section{Ethics approval and consent to participate}

The study was approved by the Ethical Research Board of Minia School of Medicine, Egypt. Ethics approval date was November 24 ${ }^{\text {th }}, 2015$. A written consent was taken from all the participants or their relatives after being informed about the objectives of the study, the examination, and the investigations. The confidentiality of their information was respected, and their right not to participate in the study was ensured.

\section{Consent for publication}

Not applicable.

\section{Competing interests}

The authors declare that they have no competing interests.

Received: 17 July 2018 Accepted: 14 July 2019

Published online: 29 July 2019

\section{References}

1. Force WTp. Stroke-1989. Recommendations on stroke prevention, diagnosis, and therapy. Report of the WHO Task Force on Stroke and other Cerebrovascular Disorders\par1989. 1407-31 \par p.

2. Air EL, Kissela BM. Diabetes, the metabolic syndrome, and ischemic stroke: epidemiology and possible mechanisms. Diabetes Care. 2007;30(12):3131-40.

3. Hinkle JL, Guanci MM. Acute ischemic stroke review. J Neurosci Nurs. 2007; 39(5):285-93,310.

4. Sacco RL. Risk factors and outcomes for ischemic stroke. Neurology. 1995; 45(2 Suppl 1):S10-4.

5. Olijhoek JK, van der Graaf Y, Banga J-D, Algra A, Rabelink TJ, Visseren FL. The metabolic syndrome is associated with advanced vascular damage in patients with coronary heart disease, stroke, peripheral arterial disease or abdominal aortic aneurysm. Euro Heart J. 2004;25(4):342-8.

6. Alberti KGM, Zimmet P, Shaw J. The metabolic syndrome-a new worldwide definition. The Lancet. 2005:366(9491):1059-62.

7. Expert Panel on Detection E. Executive summary of the third report of the National Cholesterol Education Program (NCEP) expert panel on detection, evaluation, and treatment of high blood cholesterol in adults (Adult Treatment Panel III). Jama. 2001;285(19):2486.

8. Adams HP Jr, Bendixen BH, Kappelle LJ, Biller J, Love BB, Gordon DL, et al. Classification of subtype of acute ischemic stroke. Definitions for use in a multicenter clinical trial. TOAST. Trial of Org 10172 in Acute Stroke Treatment. Stroke. 1993;24(1):35-41.

9. Organization WH. Definition, diagnosis and classification of diabetes mellitus and its complications: report of a WHO consultation. Part 1, diagnosis and classification of diabetes mellitus. Geneva: World health organization; 1999

10. Ashtari F, Salari M, Aminoroaya A, Deljoo BK, Moeini M. Metabolic syndrome in ischemic stroke: a case control study. J Res Med Sci. 2012;17(2):167.

11. Mathew B. Incidence of metabolic syndrome in ischemic stroke patients in South Indian population. Int J Pharm Phytopharma Res. 2014;3(2):110-3.

12. Liu B, Zhang Y-h, Jiang Y, Li L-I, Chen Q, He G-q, et al. Gadd45b is a novel mediator of neuronal apoptosis in ischemic stroke. Int J Biol Sci. 2015;11(3):353.

13. Natalia C, Stanislav G. Metabolic syndrome as a risk factor for ischemic stroke. The Moldovan Medical Journal. 2017;60(1):20-1.

14. Boden-Albala B. Stroke risk and the metabolic syndrome: findings from the Northern Manhattan Study. Neurology. 2003;60(1):A255-A6.
15. Koren-Morag N, Goldbourt U, Tanne D. Relation between the metabolic syndrome and ischemic stroke or transient ischemic attack: a prospective cohort study in patients with atherosclerotic cardiovascular disease. Stroke. 2005:36(7):1366-71.

16. Najarian RM, Sullivan LM, Kannel WB, Wilson PW, D'Agostino RB, Wolf PA. Metabolic syndrome compared with type 2 diabetes mellitus as a risk factor for stroke: the Framingham Offspring Study. Archives of internal medicine. 2006;166(1):106-11.

17. Kotani K, Satoh-Asahara N, Nakakuki T, Yamakage H, Shimatsu A, Tsukahara T. Association between metabolic syndrome and multiple lesions of intracranial atherothrombotic stroke: a hospital-based study. Cardiovasc Diabetol. 2015;14(1):108.

18. Rao VS, Kakkar W. Friend turns foe: transformation of anti-inflammatory HDL to proinflammatory HDL during acute-phase response. Cholesterol. 2011;2011.

19. Khovidhunkit W, Kim M-S, Memon RA, Shigenaga JK, Moser AH, Feingold KR, et al. Effects of infection and inflammation on lipid and lipoprotein metabolism: mechanisms and consequences to the host. J Lipid Res. 2004;45(7):1169-96.

20. Esteve E, Ricart W, Fernandez-Real JM. Dyslipidemia and inflammation: an evolutionary conserved mechanism. Clin Nutrition. 2005;24(1):16-31.

21. Zeljkovic A, Vekic J, Spasojevic-Kalimanovska V, Jelic-Ivanovic Z, Bogavac-Stanojevic N, Gulan B, et al. LDL and HDL subclasses in acute ischemic stroke: prediction of risk and short-term mortality. Atherosclerosis. 2010;210(2):548-54.

\section{Publisher's Note}

Springer Nature remains neutral with regard to jurisdictional claims in published maps and institutional affiliations.

\section{Submit your manuscript to a SpringerOpen ${ }^{\circ}$ journal and benefit from:}

- Convenient online submission

- Rigorous peer review

- Open access: articles freely available online

- High visibility within the field

- Retaining the copyright to your article

Submit your next manuscript at $\boldsymbol{\nabla}$ springeropen.com 